Check for updates

Cite this: RSC Adv., 2018, 8, 12742

\title{
Pt-grown carbon nanofibers for detection of hydrogen peroxide $\uparrow$
}

\author{
Noora Isoaho, (D) ${ }^{a}$ Sami Sainio, ${ }^{\mathrm{b}}$ Niklas Wester, ${ }^{\mathrm{b}}$ Luis Botello, (D) $\mathrm{d}$ \\ Leena-Sisko Johansson, ${ }^{c}$ Emilia Peltola, (D) ${ }^{a}$ Victor Climent, ${ }^{d}$ Juan M. Feliu, ${ }^{d}$ \\ Jari Koskinen (D) ${ }^{\mathrm{b}}$ and Tomi Laurila*a
}

Removal of left-over catalyst particles from carbon nanomaterials is a significant scientific and technological problem. Here, we present the physical and electrochemical study of application-specific carbon nanofibers grown from Pt-catalyst layers. The use of Pt catalyst removes the requirement for any cleaning procedure as the remaining catalyst particles have a specific role in the end-application. Despite the relatively small amount of Pt in the samples $(7.0 \pm 0.2 \%)$, they show electrochemical features closely resembling those of polycrystalline $\mathrm{Pt}$. In $\mathrm{O}_{2}$-containing environment, the material shows two separate linear ranges for hydrogen peroxide reduction: 1-100 $\mu \mathrm{M}$ and 100-1000 $\mu \mathrm{M}$ with sensitivities of 0.432 $\mu \mathrm{A} \mu \mathrm{M}^{-1} \mathrm{~cm}^{-2}$ and $0.257 \mu \mathrm{A} \mu \mathrm{M}^{-1} \mathrm{~cm}^{-2}$, respectively, with a $0.21 \mu \mathrm{M}$ limit of detection. In deaerated solution, there is only one linear range with sensitivity $0.244 \mu \mathrm{A} \mu \mathrm{M}^{-1} \mathrm{~cm}^{-2}$ and $0.22 \mu \mathrm{M}$ limit of detection. We suggest that the high sensitivity between $1 \mu \mathrm{M}$ and $100 \mu \mathrm{M}$ in solutions where $\mathrm{O}_{2}$ is present is due to oxygen reduction reaction occurring on the CNFs producing a small additional cathodic contribution to the measured current. This has important implications when Pt-containing sensors are utilized to detect hydrogen peroxide reduction in biological, $\mathrm{O}_{2}$-containing environment.

Received 26th February 2018

Accepted 28th March 2018

DOI: $10.1039 / \mathrm{c} 8 \mathrm{ra01703d}$

rsc.li/rsc-advances enzymatic biosensors utilizing certain oxidases is based on electrochemical detection of $\mathrm{H}_{2} \mathrm{O}_{2}$ which is one of the products from oxidation of the substrate molecule. Thus, detecting $\mathrm{H}_{2} \mathrm{O}_{2}$ accurately and reliably is important in the biomedical field.

Discovery of carbon nanotubes (CNTs) in the early 90's (ref. 5) started widespread interest in the research of various carbon nanomaterials. Carbon is relatively inexpensive and abundant material with large number of allotropes and tunable properties which makes it an ideal option for development of sensor applications. ${ }^{6}$ Moreover, carbon materials often have functional groups that allow immobilization of enzymes via covalent bonds making them good platforms for enzymatic biosensors. Different carbon materials can also be combined to give new hybrid materials with enhanced properties. For example, CNTs grown from tetrahedral amorphous carbon (ta-C) have been shown to induce selectivity between oxidation of dopamine and ascorbic acid, which would otherwise give overlapping signals in the voltammograms. ${ }^{7}$ In addition to CNTs, carbon nanofibers (CNFs) can also be grown from ta-C. Growing the CNFs from another carbon material, here ta-C, offers an additional carbon source and changes the fiber morphology from bamboo-like to stacked platelet-like structure. ${ }^{8}$

$\mathrm{Ni}$ is often utilized as catalyst metal for the growth of CNFs. However, some of the catalyst remains at the tips of the fibers and cannot be completely removed for example by treating the samples with concentrated acid. ${ }^{9}$ Moreover, when aiming to develop applications for possible future in vivo use in

\footnotetext{
${ }^{a}$ Department of Electrical Engineering and Automation, School of Electrical Engineering, Aalto University, PO Box 13500, 00076 Aalto, Finland. E-mail: tomi. laurila@aalto.fi; Tel: +358503414375

${ }^{b}$ Department Chemistry and Materials Science, School of Chemical Technology, Aalto University, PO Box 16200, 00076 Aalto, Finland

${ }^{c}$ Department of Bioprocess and Biosystems, School of Chemical Technology, Aalto University, PO Box 16300, 00076 Aalto, Finland

${ }^{d}$ Instituto de Electroquimica, Universidad de Alicante, Apt. 99, 03080 Alicante, Spain $\dagger$ Electronic supplementary information (ESI) available. See DOI: 10.1039/c8ra01703d
} 
electrochemical sensors, nickel should be avoided as it is a common contact allergen. ${ }^{10} \mathrm{We}$ have previously presented the use of application-specific catalyst layers in fabrication of Ptcontaining carbon nanofibers (Pt-CNFs). ${ }^{11}$ From $10 \mathrm{~nm}$ thick $\mathrm{Pt}$ layer with underlaying ta-C thin film it is possible to grow CNFs with height up to several hundreds of nanometers. Pt is present in these fibers as a larger particle at the tip and as smaller particles along the length of the fibers. Even though part of the Ti used as adhesion layer was distributed as fine particles in the fibers, it did not visibly affect the electrochemical response. The advantages of this novel hybrid carbon nanomaterial include the well-ordered structure and control over the location where fibers are grown, which is important from the device fabrication point of view. The preliminary results showed that this novel hybrid carbon nanomaterial could be utilized for $\mathrm{H}_{2} \mathrm{O}_{2}$ detection. Here, we proceed to the in depth structural and electrochemical characterization of the PtCNFs and especially asses the roles of dissolved oxygen and chloride ions on the electrochemical performance. To verify the crucial role of Pt nanoparticles in the electrochemical behavior of the CNFs, carbon nanofibers grown from nanodiamonds were utilized as a metal-free reference.

\section{Experimental}

\subsection{Sample preparation}

Samples were prepared on boron doped p-type $\mathrm{Si}(100)$ wafers with $0.005 \Omega \mathrm{cm}$ resistivity (Siegert, Germany). The wafer was first coated with a $20 \mathrm{~nm}$ Ti adhesion layer with direct current magnetron sputtering. Next, $7 \mathrm{~nm}$ ta-C was deposited on top of the Ti layer by pulsed filtered cathodic vacuum arc deposition in base pressure below $1.3 \times 10^{-4} \mathrm{~Pa}$. Before CNF growth $10 \mathrm{~nm} \mathrm{Pt}$ catalyst layer was deposited also with cathodic arc deposition. More detailed description of the deposition procedures can be found in our earlier publication ${ }^{\mathbf{1 2}}$ with the difference that here instead of using a gradient function for the deposition, first only carbon was sputtered from one cathode and then only Pt from another cathode. Finally, samples were placed in the cold-wall plasma-enhanced chemical vapor deposition reactor (Aixtron, Black Magic, Germany) and CNF were grown as described in detail in our previous publication. ${ }^{11}$ In brief, $\mathrm{NH}_{3} / \mathrm{C}_{2} \mathrm{H}_{2}$ gas mixture $(125 / 30 \mathrm{sccm})$ was injected to the reactor at growth temperature of $750{ }^{\circ} \mathrm{C}$ for 30 minutes. In addition to using $\mathrm{Pt}$ as catalyst, nanofibers were also grown from carboxyl functionalized zeta-negative nanodiamonds (NDs, Carbodeon uDiamonds, Carbodeon, Vantaa, Finland) in order to obtain a metal-free reference material for the Pt-CNFs. The concentration of the original waterbased ND solution was $5 \mathrm{wt} \%$ and it was diluted into $0.05 \mathrm{wt} \%$ in ethanol. The NDs were deposited on the silicon chips by spray coating with pressurized air (3.5 bar) as the carrying gas. The distance between the spray gun and samples was $10 \mathrm{~cm}$. Scanning over the samples was repeated 10 times. CNF growth process was the same as for the Pt-CNF samples except for the growth time which was $30 \mathrm{~min}$ and temperature which was $600{ }^{\circ} \mathrm{C}$.

In addition to the ND-CNFs also $10 \mathrm{~nm}$ Pt thin film samples and spherical polycrystalline Pt electrode were utilized for comparison in electrochemical experiments.
For electrochemical experiments (cyclic voltammetry and amperometry) a circular area (varying geometric areas) was defined with PTFE tape. For rotating disk electrode experiments a special holder with radius of $3 \mathrm{~mm}$ was utilized.

\subsection{Physical characterization}

HRTEM samples were prepared by focused ion beam (FIB) milling using polymer ink as filler material. 70-80 nm Pt and Pt-C (FIB deposited) were used to protect the CNFs during sample fabrication. Double aberration-corrected microscope (JEOL 2100, Japan) equipped with an X-ray detector was utilized for high-resolution TEM imaging. Digital recording was performed with a Gatan $4 \times 4$ UltraScan 4000 CCD camera.

SEM images were obtained with Zeiss Sigma VP. Sample were mounted on holders (planar and cross-sectional) with double-sided carbon tape and $\mathrm{Cu}$ tape. No additional coating was used.

XPS measurements were performed with Kratos AXIS Ultra Xray photoelectron spectroscope (Kratos Analytical, Manchester, $\mathrm{UK})$ using monochromated $\mathrm{Al} \mathrm{K} \alpha \mathrm{X}$-ray irradiation at $100 \mathrm{~W}$. Samples were pre-evacuated in sample transfer chamber overnight. Both survey-spectra and high-resolution spectra of $\mathrm{C} 1 \mathrm{~s}$, $\mathrm{O}$ 1s and Pt $4 \mathrm{f}$ was collected from three locations per sample. Cellulose filter paper (Whatman) was used as an internal in situ ref. 13 Analysis depth was expected to be $<10 \mathrm{~nm}$ and area $400 \times$ $800 \mu^{2}$. CasaXPS software was used for both extracting the elemental atomic percentages from the survey spectra and fitting the $\mathrm{C}$ 1s and $\mathrm{Pt}$ 4f high-resolution regimes (Shirleybackground with assumed Gaussian line shapes). The reported cellulose in situ reference was used for charge correcting the binding energies, where $286.7 \mathrm{eV}$ was assigned for carbon atoms bonded to single oxygen atom. ${ }^{\mathbf{1 4}}$

\subsection{Electrochemical experiments}

All electrochemical experiments were performed with either Gamry Reference 600 or 600 + potentiostat (Gamry Instruments) with $\mathrm{Ag} / \mathrm{AgCl} / \mathrm{KCl}$ sat'd reference electrode (Radiometer Analytical) and Pt wire counter electrode. To address the difference in $\mathrm{pH}$ some of the results are presented against RHE. The conversion was done by utilizing Nernst equation taking into account solution $\mathrm{pH}$. Rotating disk electrode (RDE) experiments were conducted by using a Radiometer Analytical rotating motor (Model EDI101). Samples used in RDE were examined in SEM before and after the experiments and despite some minor agglomeration the fibers retained their vertical alignment. Amperometric experiments were performed by stepping the potential from $0 \mathrm{~V}$ to $-0.15 \mathrm{~V} v s$. $\mathrm{Ag} / \mathrm{AgCl}$. Between measurements the solution was mixed either with magnetic stirrer or bubbling with $\mathrm{N}_{2}$. The magnetic stirrer was off during the measurement.

Unless stated otherwise, the solution were purged with $\mathrm{N}_{2}$ before starting the experiment and gas blanket was used during the measurements. The electrochemical characterization was performed by scanning in $0.15 \mathrm{M} \mathrm{H}_{2} \mathrm{SO}_{4}$ (diluted from $95-97 \%$ $\mathrm{H}_{2} \mathrm{SO}_{4}$, Merck Millipore) at $50 \mathrm{mV} \mathrm{s}{ }^{-1}$. Scanning was also repeated in phosphate buffered saline (PBS, $\mathrm{pH}$ 7.4) containing 
$\mathrm{NaCl}(137 \mathrm{mM}), \mathrm{KCl}(2.7 \mathrm{mM}), \mathrm{Na}_{2} \mathrm{HPO}_{4}(10 \mathrm{mM})$ and $\mathrm{KH}_{2} \mathrm{PO}_{4}$ $(1.8 \mathrm{mM})$ as well as phosphate buffer without chlorides $\left(\mathrm{PB}_{\mathrm{Na}}\right.$, $\mathrm{pH}$ 7.2) containing $\mathrm{H}_{2} \mathrm{NaPO}_{4}(30 \mathrm{mM})$ and $\mathrm{HNa}_{2} \mathrm{PO}_{4}(70 \mathrm{mM})$. Samples were also characterized in $1 \mathrm{mM}$ hexaammineruthenium(III) chloride ( $\mathrm{Ru}\left(\mathrm{NH}_{3}\right)_{6} \mathrm{Cl}_{3}$, Aldrich, 98\%) in $1 \mathrm{M} \mathrm{KCl}$. $\mathrm{H}_{2} \mathrm{O}_{2}$ stock solutions were prepared from $30 \% \mathrm{H}_{2} \mathrm{O}_{2}$ (Merck KGaA, Germany) by diluting in deionized water.

For comparison, phosphate buffer $\left(\mathrm{PB}_{\mathrm{K}}, \mathrm{pH}\right.$ 7.2) was also prepared using potassium phosphates instead of sodium phosphates. To assess the effect of $\mathrm{pH}$ and adding phosphates a solution containing both $0.1 \mathrm{M} \mathrm{H}_{2} \mathrm{SO}_{4}$ and $0.1 \mathrm{M} \mathrm{KH}_{2} \mathrm{PO}_{4}$ was prepared (pH 1.3).

\section{Results and discussion}

\subsection{Characterization}

The SEM micrographs in Fig. 1 show that the CNFs form a thick forest of fibers with average length of approximately $500 \mathrm{~nm}$. From the top view image (Fig. 1B) it can be seen that the fibers form bundles with some tens of nanometers between them. The catalyst particles are also clearly visible in the SEM micrographs. Especially the top view illustrates the size of the particles varies considerably, possibly partly due to the bundling of the fibers. HRTEM micrographs in Fig. 1C and D show the fibers and the catalyst particles in more detail. Together with the SEM images (Fig. 1A), the HRTEM micrograph in Fig. 1C highlights that the length of the fibers varies from approximately $60 \mathrm{~nm}$ to $600 \mathrm{~nm}$. This is somewhat shorter than presented in our previous publication ${ }^{\mathbf{1 1}}$ where the lengths of the fibers were observed to span from few hundreds of nanometers to even up to micrometer scale. This is explained by the shorter growth period (30 min vs. $60 \mathrm{~min}$ ) for the sample batch used here as well as the stochastic growth process. It is visible from Fig. 1D that some of the catalyst Pt particles at the tips of the fibers are in fact single crystals. However, as presented in the electrochemical characterization section below, the Pt-CNF show polycrystalline-like behavior when cycled for example in $\mathrm{H}_{2} \mathrm{SO}_{4}$, indicating that the particles are not terminated in any preferential orientation. Such lack of preferential orientation might be a consequence of the oxidation and reduction cycles applied during the cleaning procedure.

The XPS spectra in Fig. 1E further verifies the presence of Pt through the Pt 4 f doublet. Moreover, it was estimated from XPS data that the amount of Pt in the samples was $7.0 \pm 0.2 \%$. Fitting the Pt $4 \mathrm{f}$ peaks (ESI Fig. S1†) showed that approximately $75 \%$ of the Pt in the samples is in metallic form and the rest as different Pt oxides. Some estimates on the nature of the oxides is provided in the ESI. $\dagger$ Interestingly the amount of Ti detected by the XPS was $7.2 \%$ which is considerably higher than for amorphous carbon films with intrinsic Pt-gradient, where all the Ti utilized as adhesion layer was buried under the thin film. ${ }^{12}$ We have previously shown that when the Pt catalyst layer is $10 \mathrm{~nm}$ in addition to the irregularly shaped Pt particles at the tips the grown fibers have finely distributed Ti along their lengths. ${ }^{11}$ However, most of the Ti adhesion layer is still intact which has been suggested to be a consequence of thick enough
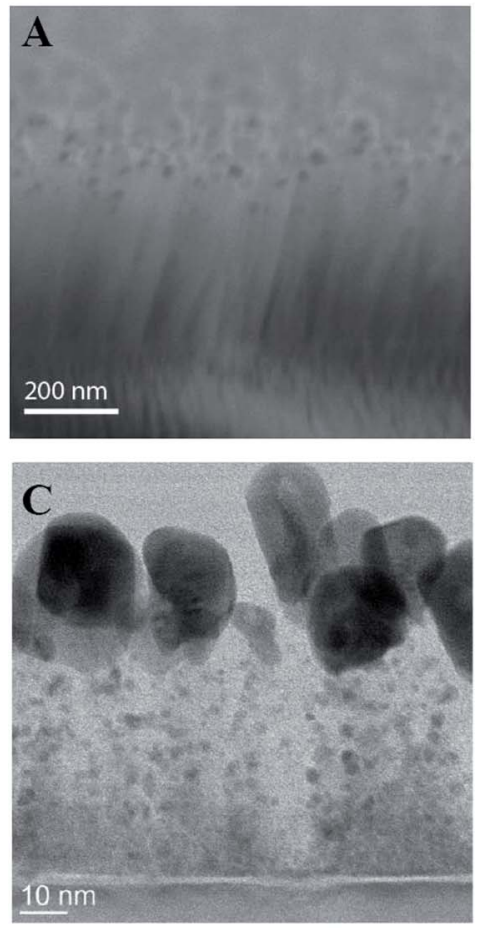
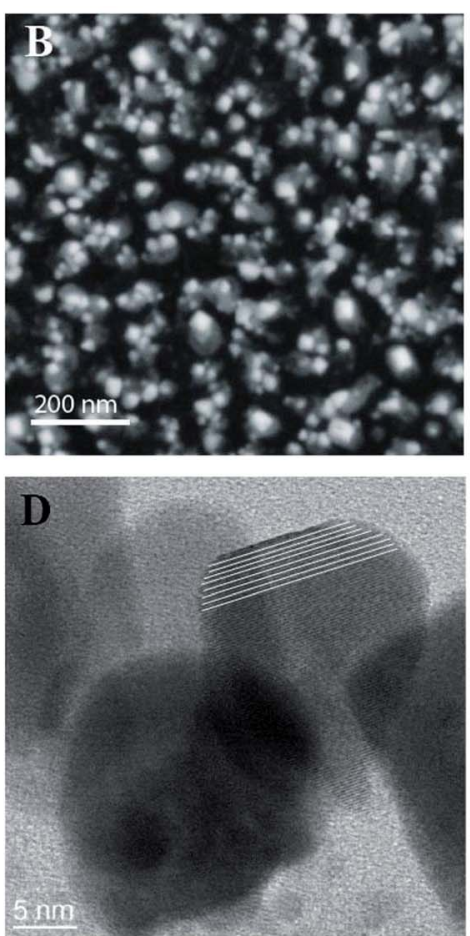

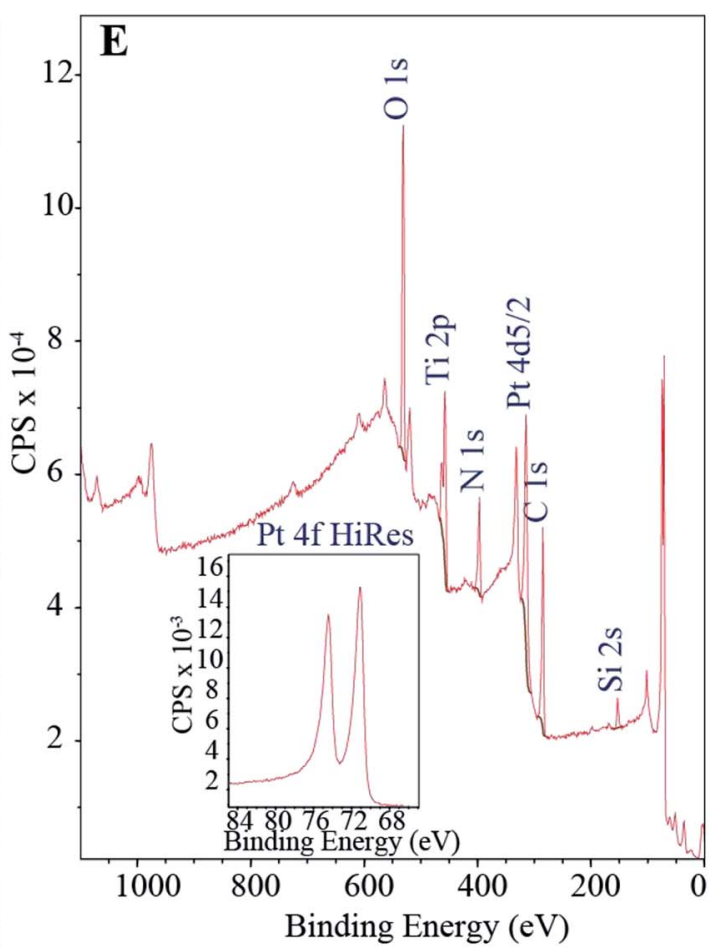

Fig. 1 SEM micrographs: tilted cross-sectional (A) and top view (B) of the fibers. The catalyst particles located in the tips are clearly visible in both images. The HRTEM micrographs ( $C$ and $D)$ show the fibers and the catalyst particles in more detail. As can be seen from the middle particle in D, some of the catalyst particles are single crystals even though the samples show mostly polycrystalline behavior (the white lines in D have been added to help guide the eye). (E) XPS wide spectrum for Pt-CNFs with the inset showing the high resolution spectrum for the Pt $4 \mathrm{f}$ doublet. 

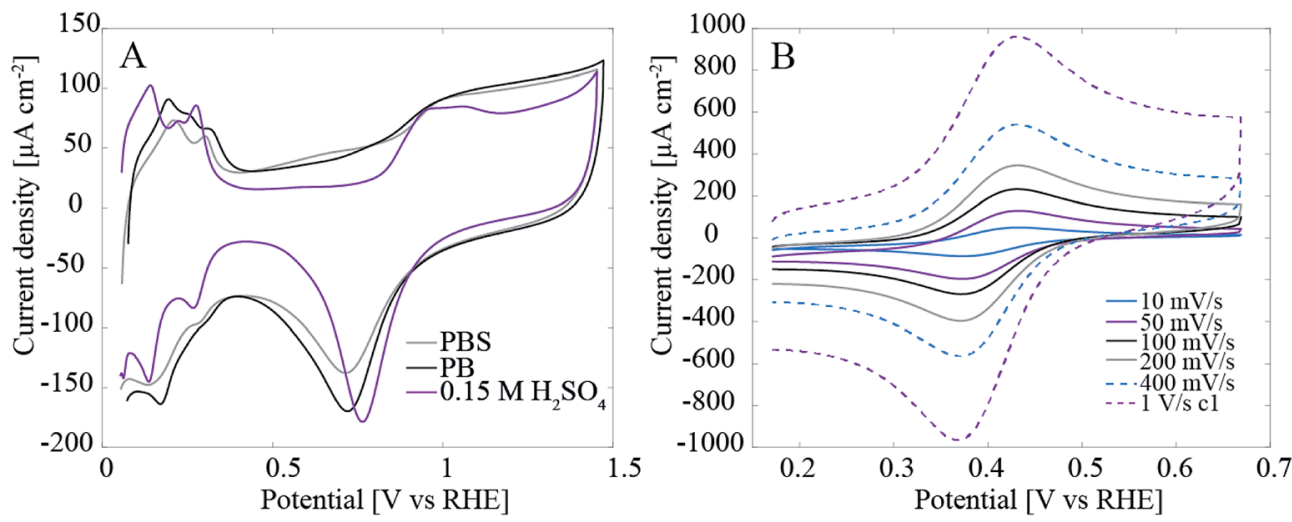

Fig. 2 (A) Voltammograms for Pt-CNFs at $50 \mathrm{mV} \mathrm{s}^{-1}$ in PBS, in phosphate buffer and in $0.15 \mathrm{M} \mathrm{H}_{2} \mathrm{SO}_{4}$. (B) Electrochemical characterization of the $\mathrm{Pt}-\mathrm{CNFs}$ in $1 \mathrm{mM} \mathrm{Ru}\left(\mathrm{NH}_{3}\right)_{6} \mathrm{Cl}_{3}$ in $1 \mathrm{M} \mathrm{KCl}$ at different scan rates. To take the $\mathrm{pH}$ difference into account the graphs in both $\mathrm{A}$ and $\mathrm{B}$ are presented in $\mathrm{RHE}$ scale even though the original measurements were performed against $\mathrm{Ag} / \mathrm{AgCl} / \mathrm{KCl}$ sat'd. Conversion was done by utilizing Nernst equation taking into account solution $\mathrm{pH}$.

catalyst layer protecting the ta-C film as well as a prerequisite for the proper fiber growth.

\subsection{Electrochemical characterization and $\mathrm{H}_{2} \mathrm{O}_{2}$ detection}

Fig. 2A shows that especially in $\mathrm{H}_{2} \mathrm{SO}_{4}$ the Pt features including oxide formation and reduction as well as hydrogen adsorption and desorption are clearly visible. The hydrogen region below $0.4 \mathrm{~V}$ vs. RHE has been denoted as the fingerprint for clean polycrystalline Pt and since especially the smaller peak at $0.2 \mathrm{~V}$ vs. RHE is only visible on very clean surfaces ${ }^{15}$ it can be said that despite the dirty initial conditions Pt can be cleaned efficiently by potential cycling. The dirty conditions refer here to the inevitable presence of carbon impurities in the solution originating from the samples themselves - that could contaminate Pt. On the other hand, in the buffer solutions all the Pt features are still visible but clearly the cleaning effect of potential cycling in this media is less efficient.

Samples were also characterized with $1 \mathrm{mM}$ hexaammineruthenium(III) chloride $\left(\mathrm{Ru}\left(\mathrm{NH}_{3}\right)_{6} \mathrm{Cl}_{3}\right.$, Aldrich, $\left.98 \%\right)$ in $1 \mathrm{M} \mathrm{KCl}$. Pt-CNFs showed reversible electron transfer kinetics: $\Delta E_{\mathrm{p}}$ increased from $59 \mathrm{mV}$ for $10 \mathrm{mV} \mathrm{s}^{-1}$ to $64 \mathrm{mV}$ for $1 \mathrm{~V} \mathrm{~s}^{-1}$ (Fig. 2B). As the electron transfer was practically reversible, the electrochemically active surface area was estimated from the data by using Randles-Sevcik equation:

$$
I_{\mathrm{P}}=\left(2.69 \times 10^{5}\right) n^{2 / 3} A D^{1 / 2} v^{1 / 2} C_{0},
$$

where $I_{\mathrm{p}}$ is the anodic peak current, $n$ is the number of transferred electrons (here $n=1$ ), $A$ is the electrochemically active surface area, $D$ is the diffusion coefficient (for $\left[\mathrm{Ru}\left(\mathrm{NH}_{3}\right)_{6}\right]^{2+}: 7.7$ $\left.\times 10^{-6} \mathrm{~cm}^{2} \mathrm{~s}^{-1}\right){ }^{16} C_{0}$ is the bulk concentration of $\mathrm{Ru}\left(\mathrm{NH}_{3}\right)_{6} \mathrm{Cl}_{3}$. The surface area was calculated for each scan rate with eqn (1) and the average was $0.062 \pm 0.003 \mathrm{~cm}^{2}$ which is $88 \%$ of the geometric area of the sample $\left(0.071 \mathrm{~cm}^{2}\right)$. The electrochemically active surface area was similarly estimated for the ND-grown nanofibers (ND-CNFs) resulting in approximately $92 \%$ of the geometric area $\left(0.031 \mathrm{~cm}^{2}\right)$. The use of Randles-Sevcik equation was justified also in this case as the ND-CNFs were also characterized with $1 \mathrm{mM} \mathrm{Ru}\left(\mathrm{NH}_{3}\right)_{6} \mathrm{Cl}_{3}$ and they showed reversible behavior (ESI, Fig. S2 $\dagger$ ). Thus, it cannot be stated that the electrochemical activity in this case would purely arise from the Pt particles. As the actual area for nanomaterials is typically larger than the geometric area this result indicates that there are certain regions that are possibly inaccessible for the electrolyte or the probe molecules. We propose that this might be due to, for example, stacking of the nanofibers. The area was also estimated from $\mathrm{CV}$ data in $0.15 \mathrm{M} \mathrm{H}_{2} \mathrm{SO}_{4}$ by integrating the area below the hydrogen desorption features using the doublelayer region current as baseline and dividing this by charge density $\left(210 \mu \mathrm{C} \mathrm{cm}^{-2}\right){ }^{17}$ The calculated area was $0.11 \mathrm{~cm}^{2}$ and it corresponds only to Pt available for hydrogen adsorption. It is not surprising that electroactive area from adsorption processes is higher than that measured from a diffusional process since it is well known that the overlay of diffusional fronts from different microroughnesses tends to decrease the area measured in this way. ${ }^{18}$ Since the electrochemical methods for active surface area measurements give contradictory results, geometric area was utilized when calculating current densities in this work.

We have previously presented initial results that showed that the Pt-CNFs are suitable for amperometric detection of $\mathrm{H}_{2} \mathrm{O}_{2}$ in $\mathrm{O}_{2}$-containing environment. ${ }^{11} \mathrm{Fig}$. 3A shows that when potential is stepped from initial value of $0 \mathrm{~V}$ to $-0.15 \mathrm{~V} v s$. $\mathrm{Ag} / \mathrm{AgCl}$ and when $\mathrm{H}_{2} \mathrm{O}_{2}$ concentration is increased by intervals of $10 \mu \mathrm{M}$ between $10 \mu \mathrm{M}$ and $100 \mu \mathrm{M}$ and by intervals of $100 \mu \mathrm{M}$ between $100 \mu \mathrm{M}$ and $1000 \mu \mathrm{M}$ (increase in volume was the same throughout the whole region) in non-deaerated PBS there are in fact two separate linear ranges: first from $1 \mu \mathrm{M}$ to $100 \mu \mathrm{M}$ with sensitivity of $0.432 \mu \mathrm{A} \mu \mathrm{M}^{-1} \mathrm{~cm}^{-2}$ and second from $100 \mu \mathrm{M}$ to $1000 \mu \mathrm{M}$ with sensitivity of $0.257 \mu \mathrm{A} \mu \mathrm{M}^{-1} \mathrm{~cm}^{-2}$. The limit of detection was $0.21 \mu \mathrm{M}(\mathrm{S} / \mathrm{N}=3)$. The limit of detection presented here is considerably larger than what we presented for the Pt-CNFs in our previous publication ( $0.2 \mathrm{nM})$. On the other hand, the sensitivities for both linear ranges are slightly higher but still in the same range as the one published previously $\left(0.148 \mu \mathrm{A} \mathrm{M} \mathrm{M}^{-1} \mathrm{~cm}^{-2}\right)$. The inconsistency between these results 

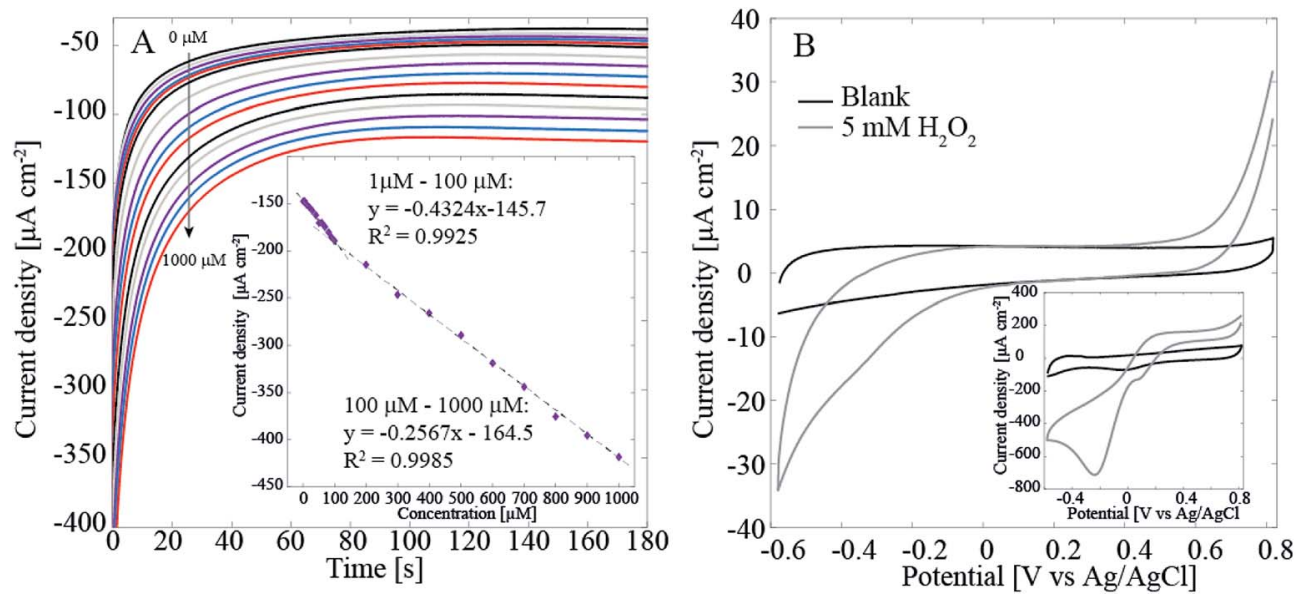

Fig. 3 (A) Amperometric detection of $\mathrm{H}_{2} \mathrm{O}_{2}$ with the Pt-CNF samples in non-deaerated PBS. The potential was stepped from 0 V to $-0.15 \mathrm{~V}$ vs. $\mathrm{Ag} / \mathrm{AgCl}$ for $180 \mathrm{~s}$. The concentration was first increased to $1 \mu \mathrm{M}$ and then to $5 \mu \mathrm{M}$. Between $10 \mu \mathrm{M}$ and $100 \mu \mathrm{M}$ the concentration was increase by steps of $10 \mu \mathrm{M}$ and above $100 \mu \mathrm{M}$ by steps of $100 \mu \mathrm{M}$. The data points were obtained by averaging the current between $0.5 \mathrm{~s}$ and $1 \mathrm{~s}$. (B) Cyclic voltammograms recorded at $50 \mathrm{mV} \mathrm{s}^{-1}$ for ND-CNFs in blank and $\mathrm{H}_{2} \mathrm{O}_{2}$-containing PBS (deaerated). Inset shows the same measurement for PtCNFs.

could, at least to some extent, arise from the variation between and within sample batches. The growth process of the fibers depends on such parameters as temperature, time period and catalyst layer thickness. In addition, the condition of the growth chamber, i.e. if it has been cleaned recently, can have an effect on the fibers. Finally, the growth process is highly stochastic
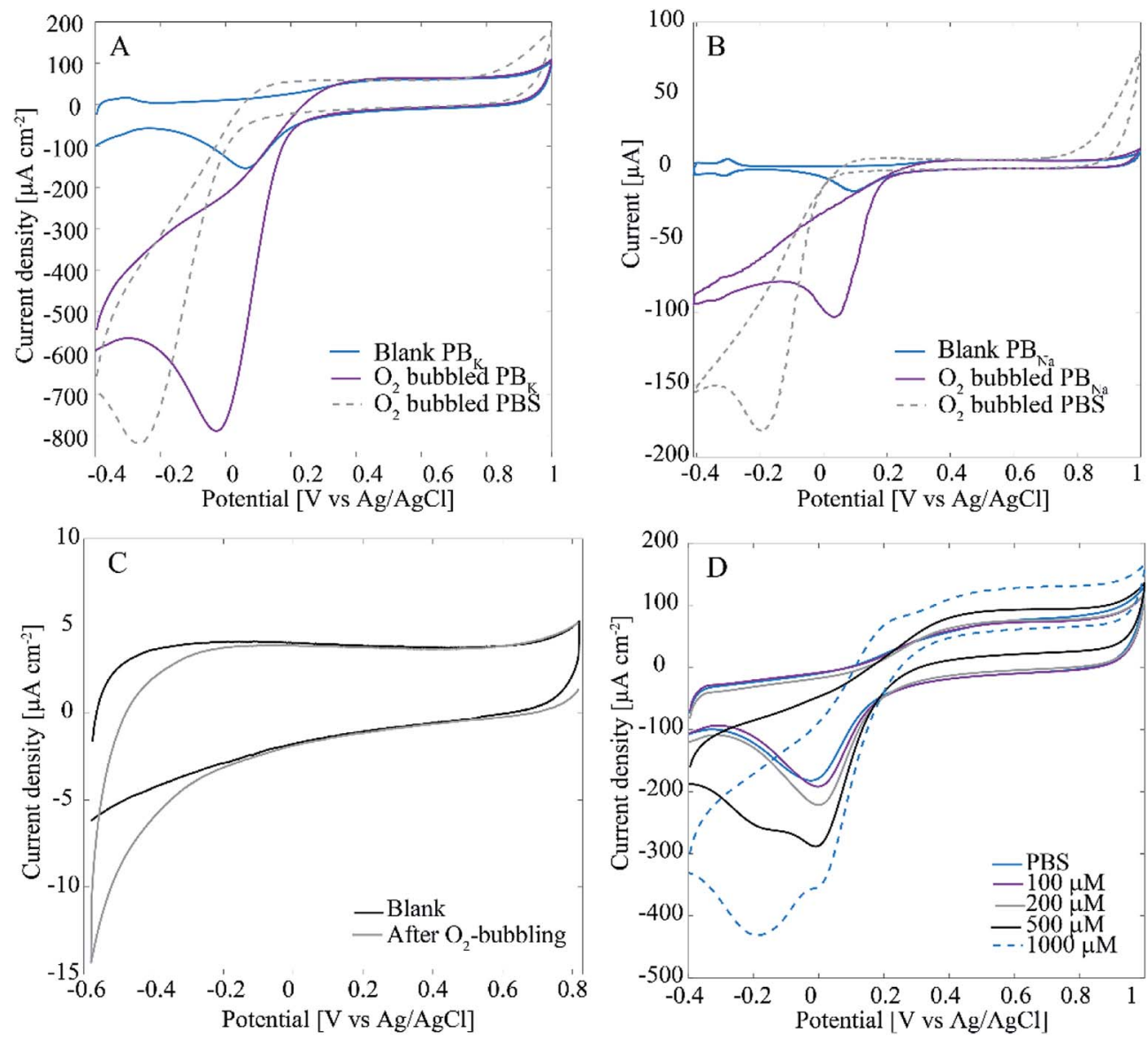

Fig. 4 (A) Voltammograms for Pt-CNFs in blank ( $\mathrm{N}_{2}$-saturated) $\mathrm{PB}_{\mathrm{K}}$ and $\mathrm{O}_{2}$-saturated $\mathrm{PB}_{\mathrm{K}}$ and $\mathrm{PBS}$. (B) Voltammograms for polycrystalline $\mathrm{Pt}$ in blank ( $\mathrm{N}_{2}$-saturated) $\mathrm{PB}_{\mathrm{Na}}$ and $\mathrm{O}_{2}$-saturated $\mathrm{PB}_{\mathrm{Na}}$ and PBS. (C) Voltammograms for ND-CNFs in blank ( $\mathrm{N}_{2}$-saturated) PBS. (D) Voltammograms for Pt-CNFs in blank and $\mathrm{H}_{2} \mathrm{O}_{2}$-containing PBS (non-deaerated). Scan rate in (A-D) was $50 \mathrm{mV} \mathrm{s}^{-1}$. 
Table 1 Resistivities and $\mathrm{pH}$ values for $\mathrm{H}_{2} \mathrm{SO}_{4}$, phosphate buffers $\left(\mathrm{PB}_{\mathrm{Na}}\right.$ and $\mathrm{PB}_{\mathrm{K}}$ ), mixed solution of $\mathrm{H}_{2} \mathrm{SO}_{4}$ and $\mathrm{KH}_{2} \mathrm{PO}_{4}$, and PBS

\begin{tabular}{lll}
\hline Solution & Resistivity $(\Omega \mathrm{cm})$ & $\mathrm{pH}$ \\
\hline $\mathrm{H}_{2} \mathrm{SO}_{4}$ & 0.58 & 0.95 \\
$\mathrm{~PB}_{\mathrm{Na}}$ & 1.48 & 7.22 \\
$\mathrm{~PB}_{\mathrm{K}}$ & 1.18 & 7.23 \\
$\mathrm{H}_{2} \mathrm{SO}_{4}+\mathrm{KH}_{2} \mathrm{PO}_{4}$ & 0.67 & 1.26 \\
$\mathrm{PBS}$ & 1.07 & 7.42 \\
\hline
\end{tabular}

which affects for example the length and diameter of the fibers (Fig. 1A and C).

To verify that the main current here arises from the $\mathrm{Pt}$ catalyst particles, we measured the reduction of $\mathrm{H}_{2} \mathrm{O}_{2}$ with the Pt-free ND-CNFs for comparison. Fig. 3B shows that even with as high concentration as $5 \mathrm{mM}$ of $\mathrm{H}_{2} \mathrm{O}_{2}$ the current density for its reduction is very small (less than 10\%) compared to the current density obtained in with Pt-CNFs (Fig. 3B inset). This supports the assumption that it is mainly Pt particles, and not the CNFs, that catalyse the reaction.

Interestingly, when measuring $\mathrm{H}_{2} \mathrm{O}_{2}$ in deaerated $\left(\mathrm{O}_{2}\right.$-free $)$ solutions there is only one linear range from $5 \mu \mathrm{M}$ to $1000 \mu \mathrm{M}$ with sensitivity of $0.244 \mu \mathrm{A} \mu \mathrm{M}^{-1} \mathrm{~cm}^{-2}$ and $0.22 \mu \mathrm{M}$ limit of detection (results not shown here). Since the only difference between the two experiments was the presence of $\mathrm{O}_{2}$ in the cell, it is assumed that it must contribute to this behavior. In fact, it is well known that Pt is an efficient catalyst for ORR. Another important phenomenon is the effect of $\mathrm{Cl}^{-}$adsorption on ORR and $\mathrm{H}_{2} \mathrm{O}_{2}$ reactions of Pt. To test these phenomena with the PtCNFs, voltammograms were recorded in $\mathrm{O}_{2}$-saturated PBS containing high concentration of $\mathrm{Cl}^{-}$and chloride-free phosphate buffers $\left(\mathrm{PB}_{\mathrm{K}}, \mathrm{PB}_{\mathrm{Na}}\right.$ ) as well as $0.15 \mathrm{M} \mathrm{H}_{2} \mathrm{SO}_{4}$ (Fig. 4A shows results only for $\mathrm{PBS}$ and $\mathrm{PB}_{\mathrm{K}}$ since $\mathrm{PB}_{\mathrm{Na}}$ and $0.15 \mathrm{M} \mathrm{H}_{2} \mathrm{SO}_{4}$ were very similar to $\mathrm{PB}_{\mathrm{K}}$ ). It has been previously shown that chlorides strongly inhibit the oxygen reduction reaction. ${ }^{19}$ For all solutions the current magnitude in the cathodic end is increased considerably indicating the presence of $\mathrm{O}_{2}$ in the solution. However, there is a clear difference for the onset and peak potentials for oxygen reduction between PBS and the other solutions: for example in $\mathrm{PB}_{\mathrm{K}}$ the current starts to decrease at $0.2 \mathrm{~V} v$ s. $\mathrm{Ag} / \mathrm{AgCl}$ reaching the peak at $0 \mathrm{~V}$ whereas for PBS ORR onset is shifted to approximately $0 \mathrm{~V}$ and the peak to $-0.2 \mathrm{~V}$. As said, the main difference in composition especially between the two phosphate buffers and PBS is the absence/presence of chlorides. PBS contains large amounts of chlorides (approximately $140 \mathrm{mM}$ ) which explains the shifting of the peak to $-0.2 \mathrm{~V}$ vs. $\mathrm{Ag} / \mathrm{AgCl}$ compared to the blank, $\mathrm{N}_{2}$-saturated

Table 2 Summary of some previous works from the last 10 years where Pt has been utilized in some form for sensors detecting $\mathrm{H}_{2} \mathrm{O}_{2}$ reduction. The studies have been divided into those where $\mathrm{H}_{2} \mathrm{O}_{2}$ has been detected in phosphate buffer and those where PBS has been used as the electrolyte (chloride-containing solution). In some studies the sensitivity was given in respect to current and not currents density. This is indicated by / $A$ in the table

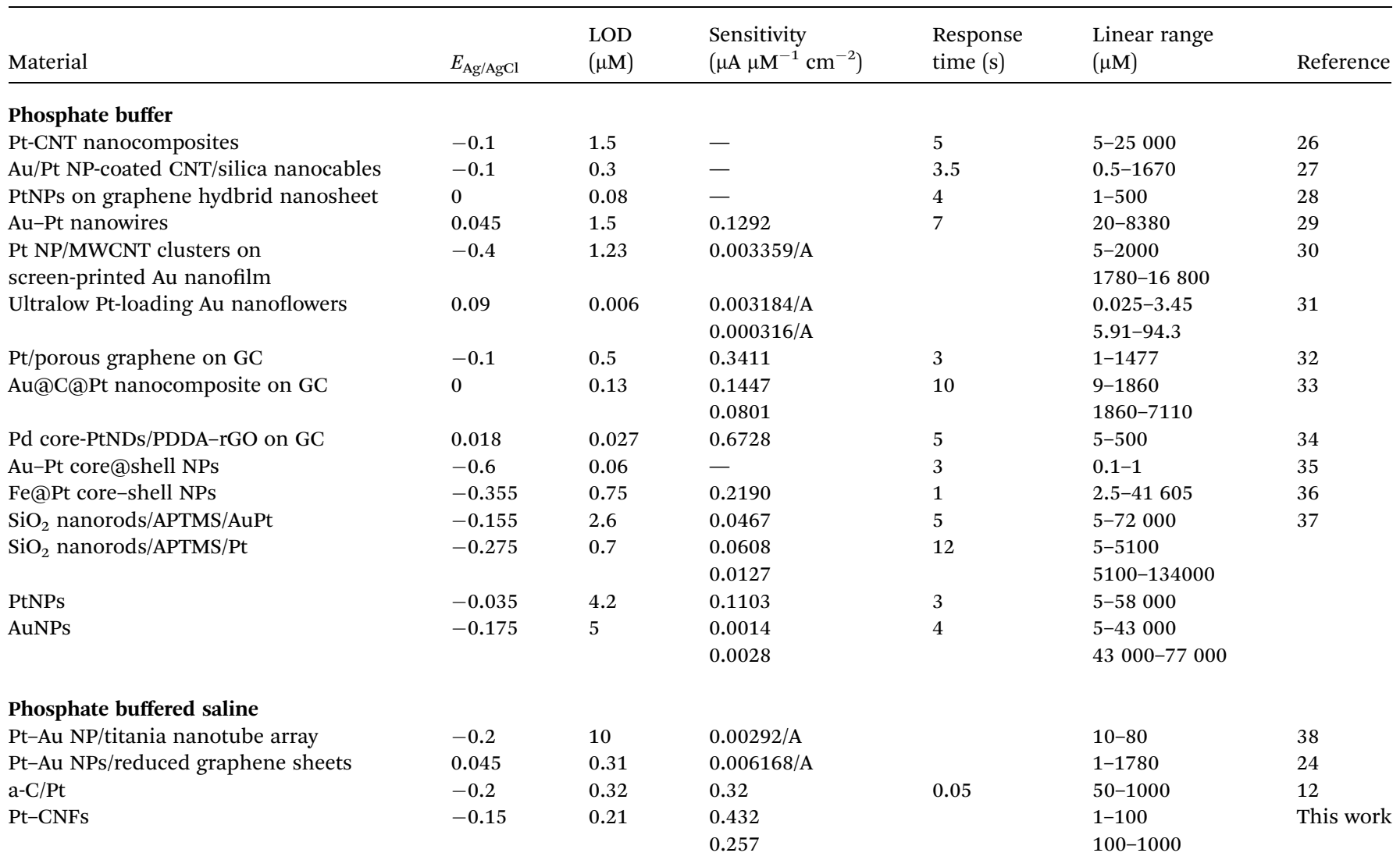



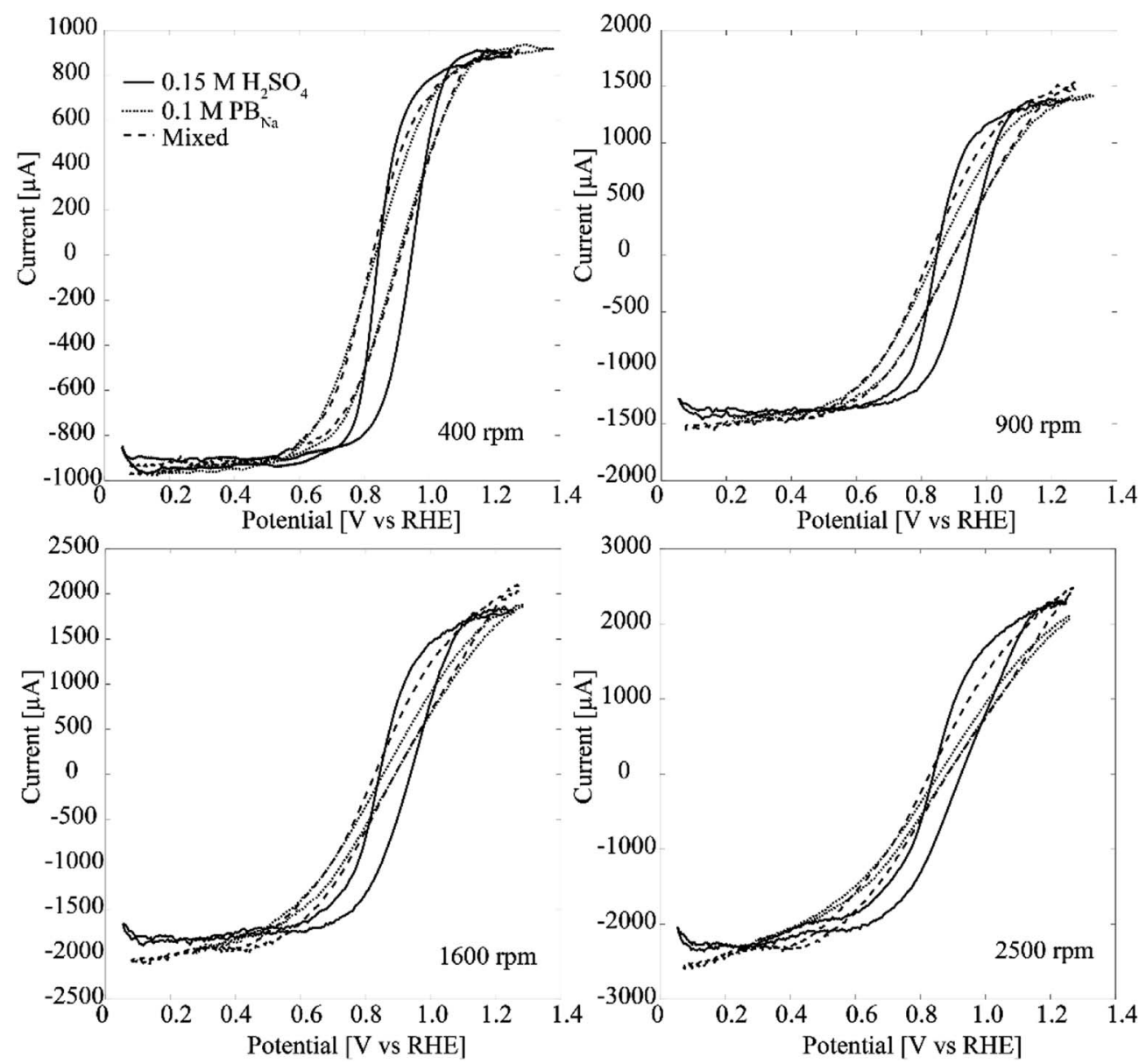

Fig. 5 RDE experiments $\left(50 \mathrm{mV} \mathrm{s}^{-1}\right.$ ) with Pt-CNFs at $400 \mathrm{rpm}, 900 \mathrm{rpm}, 1600 \mathrm{rpm}$ and at $2500 \mathrm{rpm}$ in $0.15 \mathrm{M} \mathrm{H}_{2} \mathrm{SO}_{4}, \mathrm{~PB}_{\mathrm{Na}}$ and mixed solution of phosphate buffer and $\mathrm{H}_{2} \mathrm{SO}_{4}$ with $5 \mathrm{mM} \mathrm{H}_{2} \mathrm{O}_{2}$. To take the $\mathrm{pH}$ difference into account the graphs are presented in RHE scale even though the original measurements were performed against $\mathrm{Ag} / \mathrm{AgCl} / \mathrm{KCl}$ sat'd. Conversion was done by utilizing Nernst equation taking into account solution $\mathrm{pH}$. In addition the ohmic drop was compensated for the $\mathrm{PB}_{\mathrm{Na}}$ by running a post iR correction $\left(R_{\mathrm{U}}=100 \Omega\right)$ in Echem Analyst software.

solution. For clarity, Fig. $4 \mathrm{~A}$ shows only the blank for $\mathrm{PB}_{\mathrm{K}}$ as it was nearly identical with that of PBS. In absence of chlorides $\left(\mathrm{PB}_{\mathrm{Na}}, \mathrm{PB}_{\mathrm{K}}\right.$ and $\left.\mathrm{H}_{2} \mathrm{SO}_{4}\right)$ oxygen reduction coincides with $\mathrm{Pt}$ oxides reduction as expected.

Fig. 4A also shows that in PBS the current magnitude is increased also at the anodic end of the curve when $\mathrm{O}_{2}$ is present. For the other solutions, the anodic end were comparable to the respective blanks. This is suggested to arise from incomplete ORR, which does not proceed to $\mathrm{H}_{2} \mathrm{O}$ in chloride-containing solution but actually produces additional $\mathrm{H}_{2} \mathrm{O}_{2}$ into the solution, which is then oxidized at anodic potentials above $0.8 \mathrm{~V} v s$. $\mathrm{Ag} / \mathrm{AgCl}$. Similar experiment was also tested with a spherical polycrystalline Pt electrode under well-controlled conditions and the results obtained (Fig. 4B) were identical to those of Pt-CNFs. The proposed production of $\mathrm{H}_{2} \mathrm{O}_{2}$ was further tested with polycrystalline Pt by reversing the potential at $0.2 \mathrm{~V} v s$. $\mathrm{Ag} / \mathrm{AgCl}$ to avoid the ORR. There was no extra anodic current compared to the blank curve which supports the suggestion that $\mathrm{H}_{2} \mathrm{O}_{2}$ is produced during the ORR (results not showed here). Finally, the experiment was also repeated with ND-CNFs (Fig. 4C). Oxygen is reduced at the cathodic end but the current (density) magnitude from ORR on carbon can be considered negligible and thus the main contribution indeed arises from Pt in the Pt-grown nanofibers. The small cathodic current arising from the ORR at the CNFs themselves and not the Pt catalyst particles provides an additional contribution to the measured currents for small $\mathrm{H}_{2} \mathrm{O}_{2}$ concentrations. This additional contribution becomes negligible as soon as the concentration of $\mathrm{H}_{2} \mathrm{O}_{2}$ becomes high enough so that the current arising from this process starts to dominate the total current. It is to be noted that the amperometric experiments were conducted at $-0.15 \mathrm{~V} v s$. $\mathrm{Ag} / \mathrm{AgCl}$ which is in the potential range for ORR. Thus, this coupling of two electrochemical processes in $\mathrm{O}_{2}$-containing solutions explains why there are two linear ranges in the non-degassed PBS and not in the $\mathrm{N}_{2}$-purged solution. This is a fact that must be taken into account when results from the literature (see Table 2) are considered.

When cycling the potential of the samples in non-deaerated PBS containing large amounts $(<500 \mu \mathrm{M})$ of $\mathrm{H}_{2} \mathrm{O}_{2}$, an additional peak appeared approximately at $-0.2 \mathrm{~V} v s$. $\mathrm{Ag} / \mathrm{AgCl}$ in the voltammogram (Fig. 4D). Similar peak appeared also in $\mathrm{N}_{2}$-purged solution but only with even higher concentration of $\mathrm{H}_{2} \mathrm{O}_{2}(1000$ $\mu \mathrm{M}$, see ESI Fig. S3 $\dagger$ ). It has been stated by Katsounaros $e t$ al. ${ }^{2}$ that at high enough anodic potentials where $\mathrm{OH}$ has been adsorbed on $\mathrm{Pt}, \mathrm{O}_{2}$ is produced in a non-electrochemical step: 

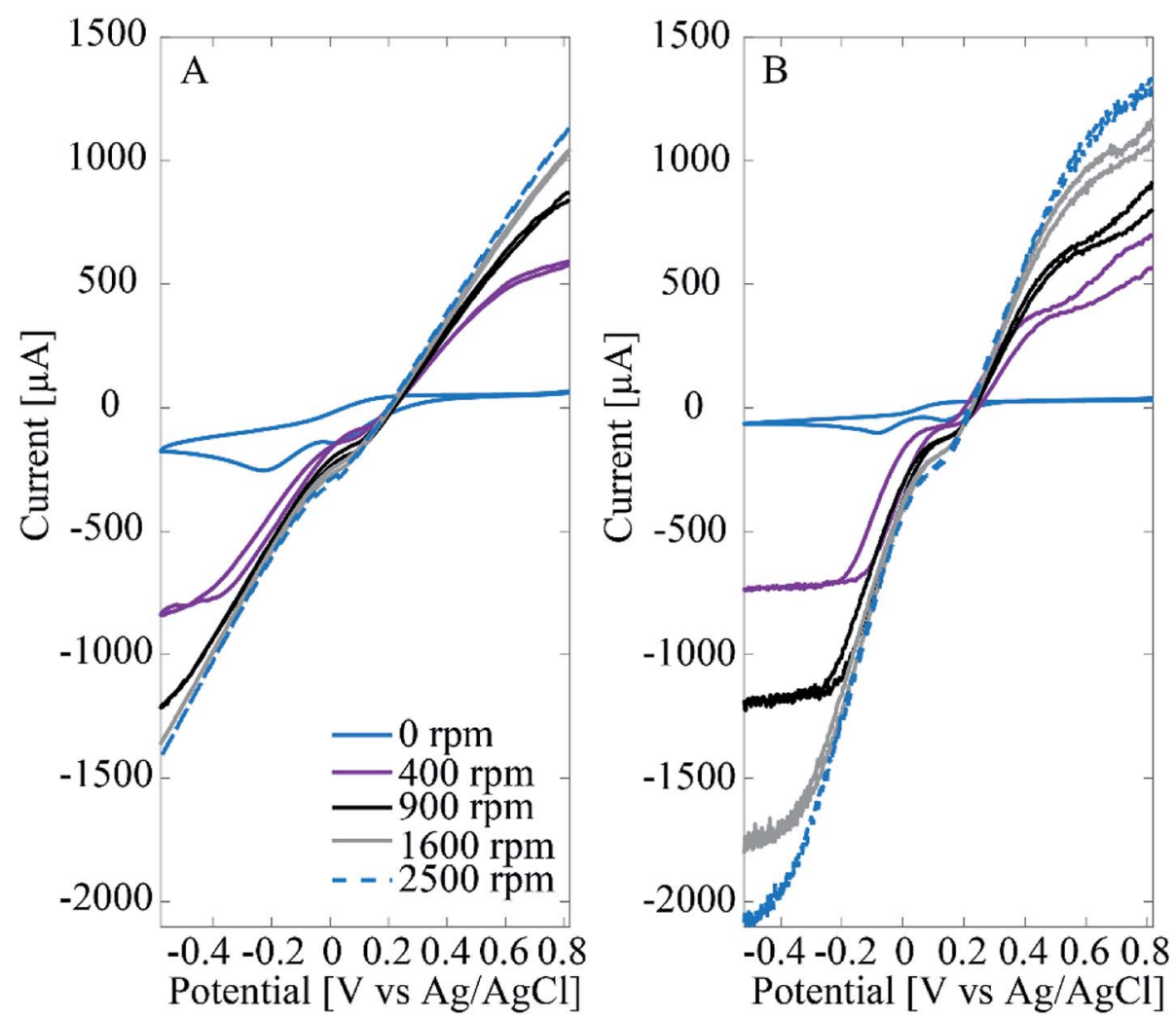

Fig. 6 RDE experiments $\left(50 \mathrm{mV} \mathrm{s}^{-1}\right.$ ) with Pt-CNFs at $400 \mathrm{rpm}, 900 \mathrm{rpm}, 1600 \mathrm{rpm}$ and at $2500 \mathrm{rpm}$ in PBS with (A) Pt-CNF and (B) $10 \mathrm{~nm}$ Pt thin film.

$$
2 \mathrm{Pt}(\mathrm{OH})+\mathrm{H}_{2} \mathrm{O}_{2} \rightarrow 2 \mathrm{Pt}\left(\mathrm{H}_{2} \mathrm{O}\right)+\mathrm{O}_{2}
$$

Thus, even in initially degassed solutions when cycling the potential in a large enough window, $\mathrm{O}_{2}$ originating from added $\mathrm{H}_{2} \mathrm{O}_{2}$ can be expected to be present. This means that in addition to hydrogen peroxide redox reactions oxygen reduction is also likely to occur. Moreover, there might be some threshold concentration for $\mathrm{O}_{2}$ since the peak only appears with addition of $\mathrm{H}_{2} \mathrm{O}_{2}$ in non-degassed solutions where $\mathrm{O}_{2}$ can be expected to be present initially. This is further supported by the peak only appearing with addition of larger amount of $\mathrm{H}_{2} \mathrm{O}_{2}$ in $\mathrm{N}_{2}$-purged PBS (Fig. S3 $\uparrow$ ). It should be noted that the peak does not appear if the upper potential limit is not high enough $(>0.5 \mathrm{~V} v s$. Ag/ $\mathrm{AgCl}$, results not shown here) which further supports the proposed origin $\left(\mathrm{OH}\right.$ has to be stable on Pt for producing $\mathrm{O}_{2}$ ).

$\mathrm{H}_{2} \mathrm{O}_{2}$ oxidation and reduction were also studied by using RDE. It is shown in Fig. 5 that compared to $0.15 \mathrm{M} \mathrm{H}_{2} \mathrm{SO}_{4}$ oxidation and reduction of $\mathrm{H}_{2} \mathrm{O}_{2}$ are kinetically hindered in $0.1 \mathrm{M}$ phosphate buffer as higher (lower) potentials are needed for reaching the limiting currents at both anodic and cathodic ends. The solution was prepared without chlorides to avoid the inhibitory effect. One explanation for the apparently slower kinetics could be that the resistivitities for the buffer solutions are higher compared to $\mathrm{H}_{2} \mathrm{SO}_{4}: 1.48 \Omega \mathrm{m}\left(\mathrm{PB}_{\mathrm{Na}}\right)$ and $1.18\left(\mathrm{~PB}_{\mathrm{K}}\right)$ vs. $0.58 \Omega \mathrm{m}$, respectively. In order to compensate this difference in resistivity a post iR correction was run for the PB data presented in Fig. 5 in Echem Analyst software for the ohmic drop (original graphs without post
iR correction are presented in the ESI as Fig. S4 $\dagger$ ). When adding $\mathrm{KH}_{2} \mathrm{PO}_{4}$ into $\mathrm{H}_{2} \mathrm{SO}_{4}$ the resistivity slightly increased to $0.67 \Omega \mathrm{m}$, which is likely a consequence of the increased pH. Fig. 5 shows that especially the $\mathrm{H}_{2} \mathrm{O}_{2}$ reduction is clearly hindered both in $\mathrm{PB}$ (iR corrected data) and the mixed solution compared to pure $\mathrm{H}_{2} \mathrm{SO}_{4}$. The effect is somewhat larger than what would be expected from the relatively small change in resistivity. On the other hand, hydrogen peroxide is reduced according to eqn (3):

$$
\mathrm{H}_{2} \mathrm{O}_{2}+2 \mathrm{H}^{+}+2 \mathrm{e}^{-} \leftrightarrow 2 \mathrm{H}_{2} \mathrm{O}
$$

which indicates that acidic environments can promote the reaction. Thus, the considerably higher $\mathrm{pH}$ of $\mathrm{PB}$ could partly explain the slower kinetics. However, as the $\mathrm{pH}$ for $\mathrm{H}_{2} \mathrm{SO}_{4}+$ $\mathrm{KH}_{2} \mathrm{PO}_{4}$ mixed solution was 1.26 compared to 0.95 for $\mathrm{H}_{2} \mathrm{SO}_{4}$, we assume that such small change is $\mathrm{pH}$ would be unlikely to have such a large effect. Resistivity and $\mathrm{pH}$ values for different solutions utilized in this study are shown in Table 1.

Since the addition of $\mathrm{KH}_{2} \mathrm{PO}_{4}$ causes a significant effect in the RDE curve especially in the cathodic end of the transition region, we suggest that this could be related to adsorption of phosphate anions. It has been shown that phosphate species adsorb on polycrystalline as well as Pt (111) and Pt (100) surfaces, with the exact nature of the adsorbed species changing with $\mathrm{pH}$ and electrode potential..$^{20-22}$

Fig. 6 shows results from RDE experiments in deaerated PBS with $5 \mathrm{mM} \mathrm{H}_{2} \mathrm{O}_{2}$ for both Pt-CNF and $10 \mathrm{~nm}$ Pt thin film 
samples. The inhibiting effect of $\mathrm{Cl}^{-}$is clear. In both Fig. 6A and $\mathrm{B}$ there is a prewave between $0.0 \mathrm{~V}$ and $0.1 \mathrm{~V}$ vs. $\mathrm{Ag} / \mathrm{AgCl}$. We propose that at larger overpotentials $\mathrm{Cl}^{-}$is desorbed and the $\mathrm{H}_{2} \mathrm{O}_{2}$ reduction is further enhanced. With the Pt thin films especially at lower rotation rates the limiting current is eventually reached, particularly in the cathodic end. However, with Pt-CNFs there is similar hindrance than seen in phosphate buffer and the mixed solution both before and after the prewave.

The main concern related to biosensors based on $\mathrm{H}_{2} \mathrm{O}_{2}$ detection that arises from the results presented here is that in biological environment it is not possible to completely avoid chlorides. This has been previously stated also by Hall et al. ${ }^{23}$ when they studied the inhibitory effect of $\mathrm{Cl}^{-}$on $\mathrm{H}_{2} \mathrm{O}_{2}$ oxidation on Pt. Table 2 summarizes some works from the last 10 years where Pt has been used in some form in sensors for $\mathrm{H}_{2} \mathrm{O}_{2}$ reduction. Majority of these studies has been in fact conducted in phosphate buffer without any chlorides. Here it has been shown that chlorides have an effect in the whole water window of $\mathrm{Pt}$ which should be taken into account when designing sensors based on $\mathrm{H}_{2} \mathrm{O}_{2}$ detection for biomedical purposes. For amperometric sensors operating at potentials where ORR is expected, special care should be taken since the production of $\mathrm{H}_{2} \mathrm{O}_{2}$ from chloride-inhibited reduction of $\mathrm{O}_{2}$ will likely affect the obtained response. $\mathrm{O}_{2}$ has been previously mentioned as cathodic interfering species for $\mathrm{H}_{2} \mathrm{O}_{2}$ detection on $\mathrm{Pt}^{24}$ and on $\mathrm{ZnO}^{25}$ in biological environment due to ORR. However, to our knowledge, the effect of additional $\mathrm{H}_{2} \mathrm{O}_{2}$ from ORR in chloridecontaining environment has not been addresses before. Moreover, in regard to enzymatic biosensors, consumption of oxygen can seriously affect the enzymatic production of $\mathrm{H}_{2} \mathrm{O}_{2}$ and consequently the sensor operation since $\mathrm{O}_{2}$ is a necessary cosubstrate for various oxidases common in biosensors.

\section{Conclusions}

Here we have presented in depth physical and electrochemical characterization of carbon nanofibers grown from Pt-catalyst. Despite some of the catalyst particles at the tips of the fibers being single crystals, the Pt-CNFs show electrochemical characteristics that resemble those of polycrystalline Pt. The PtCNFs are suitable for $\mathrm{H}_{2} \mathrm{O}_{2}$ detection: in $\mathrm{O}_{2}$ containing solutions there are two separate linear ranges, $1-100 \mu \mathrm{M}$ and $100-1000$

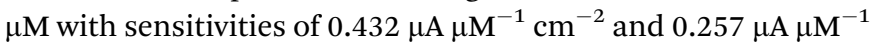
$\mathrm{cm}^{-2}$, respectively. The limit of detection was $0.21 \mu \mathrm{M}$. In deaerated solutions they show wide linear range between $5 \mu \mathrm{M}$ and $1000 \mu \mathrm{M}$ for $\mathrm{H}_{2} \mathrm{O}_{2}$ with sensitivity of $0.244 \mu \mathrm{A} \mu \mathrm{M}^{-1} \mathrm{~cm}^{-2}$ (similar to the second linear range in $\mathrm{O}_{2}$-containing solution) and $0.22 \mu \mathrm{M}$ limit of detection. We suggest that these observations are the consequence of ORR occurring on the surfaces of CNFs in $\mathrm{O}_{2}$-containing solutions, which produces a small additional cathodic current that contributes to the total measured current, the effect being significant especially at low concentrations of added $\mathrm{H}_{2} \mathrm{O}_{2}$. Also, when chlorides are present in the measurement medium, their inhibiting effect on the ORR on Pt nanoparticles will heavily affect the measurements at the higher $(>500 \mu \mathrm{M})$ region. Thus, when designing $\mathrm{H}_{2} \mathrm{O}_{2}$ sensors for biological applications the effect of chlorides and dissolved oxygen on the measured response should be taken into account as both are difficult to avoid in the above stated applications.

\section{Conflicts of interest}

There are no conflicts to declare.

\section{Acknowledgements}

Academy of Finland (E. P. grant \#274670, T. L. grant \#285526), Biocentrum Helsinki and Finnish Cultural Foundation are acknowledged for funding. J. F. and V. C. acknowledge financial funding from the Ministerio de Economia, Industria y Competitividad (CTQ2016-76221 P). M. Meyyappan and Jessica E. Koehne from NASA Ames Research Center are acknowledged for provision of facilities for growing the CNFs. The authors also acknowledge the provision of facilities at Micronova Nanofabrication Center, XPS facilities at Aalto Bioeconomy Infrastructure and OtaNano - Nanomicroscopy Center (Aalto-NMC).

\section{References}

$1 \mathrm{H}$. S. Wroblowa, Yen-Chi-Pan and G. Razumney, Electroreduction of Oxygen:A New Mechanistic Criterion, $J$. Electroanal. Chem. Interfacial Electrochem., 1976, 69, 195-201.

2 I. Katsounaros, W. B. Schneider, J. C. Meier, U. Benedikt, P. U. Biedermann, A. A. Auer and K. J. J. Mayrhofer, Hydrogen Peroxide Electrochemistry on Platinum: Towards Understanding the Oxygen Reduction Reaction Mechanism, Phys. Chem. Chem. Phys., 2012, 14, 7384-7391.

3 T. Finkel and N. J. Holbrook, Oxidants, Oxidative Stress and the Biology of Ageing, Nature, 2000, 408, 239-247.

4 S. G. Rhee, $\mathrm{H}_{2} \mathrm{O}_{2}$, A Necessary Evil for Cell Signaling, Science, 2006, 312, 1882-1883.

5 S. Iijima, Helical Microtubules of Graphitic Carbon, Nature, 1991, 354, 56-58.

6 T. Laurila, S. Sainio and M. A. Caro, Hybrid Carbon Based Nanomaterials for Electrochemical Detection of Biomolecules, Prog. Mater. Sci., 2017, 88, 499-594.

7 S. Sainio, T. Palomäki, S. Rhode, M. Kauppila, O. Pitkänen, T. Selkälä, G. Toth, M. Moram, K. Kordas, J. Koskinen and T. Laurila, Carbon Nanotube (CNT) Forest Grown on Diamond-Like Carbon (DLC) Thin Films Significantly Improves Electrochemical Sensitivity and Selectivity Towards Dopamine, Sens. Actuators, B, 2015, 211, 177-186.

8 T. Laurila, S. Sainio, H. Jiang, J. Koskinen, J. Koehne and M. Meyyappan, The Role of Extra Carbon Source During the Pre-Annealing Stage in the Growth of Carbon Nanofibers, Carbon, 2016, 100, 351-354.

9 S. Sainio, D. Nordlund, R. Gandhiraman, H. Jiang, J. Koehne, J. Koskinen, M. Meyyappan and T. Laurila, What Does Nitric Acid Really Do to Carbon Nanofibers?, J. Phys. Chem. C, 2016, 120, 22655-22662.

10 V. Mahler, J. Geier and A. Schnuch, Current Trends in Patch Testing - New Data from the German Contact Dermatitis Research Group (DKG) and the Information Network of 
Departments of Dermatology (IVDK), JDDG, Journal der Deutschen Dermatologischen Gesellschaft, 2014, 12, 583-592.

11 T. Laurila, S. Sainio, H. Jiang, N. Isoaho, J. E. Koehne, J. Etula, J. Koskinen and M. Meyyappan, Application-Specific Catalyst Layers: Pt-Containing Carbon Nanofibers for Hydrogen Peroxide Detection, ACS Omega, 2017, 2, 496-507.

12 N. Isoaho, N. Wester, E. Peltola, L.-S. Johansson, A. Boronat, J. Koskinen, J. Feliu, V. Climent and T. Laurila, Amorphous Carbon Thin Film Electrodes with Intrinsic Pt-Gradient for Hydrogen Peroxide Detection, Electrochim. Acta, 2017, 251, $60-70$.

13 L.-S. Johansson and J. M. Campbell, Reproducible XPS on Biopolymers: Cellulose Studies, Surf. Interface Anal., 2004, 36, 1018-1022.

14 G. Beamson and D. Briggs, High Resolution XPS of Organic Polymers, Wiley, Chichester, 1992.

15 V. Climent and J. M. Feliu, Thirty Years of Platinum Single Crystal Electrochemistry, J. Solid State Electrochem., 2011, 15, 1297-1315.

16 Y. Wang, J. G. Limon-Petersen and R. G. Compton, Measurement of the Diffusion Coefficients of $\left[\mathrm{Ru}\left(\mathrm{NH}_{3}\right)_{6}\right]^{3+}$ and $\left[\mathrm{Ru}\left(\mathrm{NH}_{3}\right)_{6}\right]^{2+}$ in Aqueous Solution Using Microelectrode Double Potential Step Chronoamperometry, J. Electroanal. Chem., 2011, 652, 13-17.

17 S. Trasatti and O. A. Petrii, Real Surface Area Measurements in Electrochemistry, Pure Appl. Pure Appl. Chem., 1991, 63, 711734.

18 A. J. Bard and L. R. Faulkner, Electrochemical methods: Fundamentals and Applications, Wiley and Sons, Hoboken, 2001.

19 I. Katsounaros, W. B. Schneider, J. C. Meier, U. Benedikt, P. U. Biedermann, A. Cuesta, A. A. Auer and K. J. J. Mayrhofer, The Impact of Spectator species on the Interaction of $\mathrm{H}_{2} \mathrm{O}_{2}$ with Platinum - Implications for the Oxygen Reduction Reaction Pathways, Phys. Chem. Chem. Phys., 2013, 15, 8058-8068.

20 F. C. Nart and T. Iwasita, On the Adsorption of $\mathrm{H}_{2} \mathrm{PO}_{4}{ }^{-}$and $\mathrm{H}_{3} \mathrm{PO}_{4}$ on Platinum: An In Situ FT-IR Study, Electrochim. Acta, 1992, 37, 385-391.

21 M. Weber, F. C. Nart, I. R. de Moraes and T. Iwasita, Adsorption of Phosphate Species on Pt(111) and Pt(100) As Studied by in Situ FTIR Spectroscopy, J. Phys. Chem., 1996, 100, 19933-19938.

22 J. Mostany, P. Martínez, V. Climent, E. Herrero and J. M. Feliu, Thermodynamic Studies of Phosphate Adsorption on Pt(111) Electrode Surfaces in Perchloric Acid Solutions, Electrochim. Acta, 2009, 54, 5836-5843.

23 S. B. Hall, E. A. Khudaish and A. L. Hart, Electrochemical Oxidation of Hydrogen Peroxide at Platinum Electrodes. Part V: Inhibition by Chloride, Electrochim. Acta, 2000, 45, 3573-3579.

24 G. Yu, W. Wu, X. Pan, Q. Zhao, X. Wei and Q. Lu, High Sensitive and Selective Sensing of Hydrogen Peroxide Released from Pheochromocytoma Cells Based on Pt-Au Bimetallic Nanoparticles Electrodeposited on Reduced Graphene Sheets, Sensors, 2015, 15, 2709-2722.

25 Q. Rui, K. Komori, Y. Tian, H. Liu, Y. Luo and Y. Sakai, Electrochemical Biosensor for the Detection of $\mathrm{H}_{2} \mathrm{O}_{2}$ from
Living Cancer Cells Based on ZnO Nanosheets, Anal. Chim. Acta, 2010, 670, 57-62.

26 Z. Wen, S. Ci and J. Li, Pt Nanoparticles Inserting in Carbon Nanotube Arrays: Nanocomposites for Glucose Biosensors, $J$. Phys. Chem. C, 2009, 113, 13482-13487.

27 S. Guo, J. Li, W. Ren, D. Wen, S. Dong and E. Wang, Carbon Nanotube/Silica Coaxial Nanocable as a Three-Dimensional Support for Loading Diverse Ultra-High-Density Metal Nanostructures: Facile Preparation and Use as Enhanced Materials for Electrochemical Devices and SERS, Chem. Mater., 2009, 21, 2247-2257.

28 S. Guo, D. Wen, Y. Zhai, S. Dong and E. Wang, Platinum Nanoparticle Ensemble-on-Graphene Hybrid Nanosheet: OnePot, Rapid Synthesis, and Used as New Electrode Material for Electrochemical Sensing, ACS Nano, 2010, 4, 3959-3968.

29 Y. Zhou, G. Yu, F. Chang, B. Hu and C.-J. Zhong, GoldPlatinum alloy Nanowires as Highly Sensitive Materials for Electrochemical Detection of Hydrogen Peroxide, Anal. Chim. Acta, 2012, 757, 56-62.

$30 \mathrm{X}$. Niu, H. Zhao, C. Chen and M. Lan, Platinum Nanoparticle-Decorated Carbon Nanotube Clusters on Screen-Printed Gold Nanofilm Electrode for enhanced Electrocatalytic Reduction of Hydrogen Peroxide, Electrochim. Acta, 2012, 65, 97-103.

31 Q. Wu, Y. Li, H. Xian, C. Xu, L. Wang and Z. Chen, Ultralow Pt-Loading Bimetallic Nanoflowers: Fabrication and Sensing Applications, Nanotechnology, 2013, 24, 025501.

32 J. Liu, X. Bo, Z. Zhao and L. Guo, Highly Exposed Pt Nanoparticles Supported on Porous Graphene for Electrochemical Detection of Hydrogen Peroxide in Living Cells, Biosens. Bioelectron., 2015, 74, 71-77.

33 Y. Zhang, Y. Li, Y. Jiang, Y. Li and S. Li, The Synthesis of Au@C@Pt Core-Double Shell Nanocomposite and Its Application in Enzyme-Free Hydrogen Peroxide Sensing, Appl. Surf. Sci., 2016, 378, 375-383.

34 Y. Zhang, C. Zhang, D. Zhang, M. Ma, W. Wang and Q. Chen, Nano-Assemblies Consisting of Pd/Pt Nanodendrites and Poly(Diallyldimethylammonium Chloride)-Coated Reduced Graphene Oxide on Glassy Carbon Electrode for Hydrogen Peroxide Sensors, Mater. Sci. Eng., C, 2016, 58, 1246-1254.

35 N. S. K. Gowthaman and S. A. John, Electroless Deposition of Gold-Platinum Core@Shell Nanoparticles on Glassy Carbon Electrode for Non-Enzymatic Hydrogen Peroxide sensing\#, J. Chem. Sci., 2016, 128, 331-338.

36 H. Mei, W. Wu, B. Yu, H. Wu, S. Wang and Q. Xia, Nonenzymatic Electrochemical Sensor Based on Fe@Pt Core-Shell Nanoparticles for Hydrogen Peroxide, Glucose and Formaldehyde, Sens. Actuators, B, 2016, 223, 68-75.

37 W. Liu, K. Hiekel, R. Hübner, H. Sun, A. Ferancova and M. Sillanpää, $\mathrm{Pt}$ and $\mathrm{Au}$ Bimetallic and Monometallic Nanostructured Amperometric Sensors for Direct Detection of Hydrogen Peroxide: Influences of Bimetallic Effect and Silica Support, Sens. Actuators, B, 2018, 255, 1325-1334.

38 Q. Kang, L. Yang and Q. Cai, An Electro-Catalytic Biosensor Fabricated with Pt-Au Nanoparticle-Decorated Titania Nanotube Array, Bioelectrochemistry, 2008, 74, 62-65. 